\title{
Relative Efficacy of High-Pressure Hot Water and High-Power Ultrasonics for Wine Oak Barrel Sanitization
}

\author{
Frank Schmid, ${ }^{1,2}$ Paul Grbin, ${ }^{1,2 *}$ Andrew Yap, ${ }^{3}$ and Vladimir Jiranek ${ }^{1,2}$
}

\begin{abstract}
A significant amount of capital and maintenance is invested in oak barrels, which contribute greatly to wine quality. If not cleaned correctly, barrels can accumulate tartrate deposits and wine spoilage organisms, which can be detrimental to wine quality. We examined the efficacy of using high-power ultrasonics (HPU) for sanitization of wine barrels using the spoilage yeast Dekkera (Brettanomyces) bruxellensis as the test organism and indirectly compared it to standard hot water washing practices. Both 1- and 3-year-old oak were investigated and no culturable cells were detected on the surface ( 0 to $2 \mathrm{~mm}$ ) or subsurface ( 2 to $4 \mathrm{~mm}$ ) of the oak after treatment with HPU in hot water $\left(60^{\circ} \mathrm{C}\right)$. Additionally, wines stored over a 12 -month period in barrels initially cleaned with hot water, cold water, or HPU did not differ in their extraction of oak compounds, nor could these wines be differentiated by a sensory panel. Thus, HPU did not adversely affect oak extraction into wine.
\end{abstract}

Key words: Dekkera (Brettanomyces) bruxellensis, high-power ultrasonics, oak barrel cleaning

Microbial spoilage, in particular by the yeast Dekkera (Brettanomyces) bruxellensis, is still a major problem for the wine industry (Loureiro and Malfeito-Ferreira 2003, Oelofse et al. 2008). At present $D$. bruxellensis can only be controlled by good wine manufacturing practices, with the aging of wines in barrels identified as the most likely point of spoilage (Oelofse et al. 2008). Thus, sanitization of oak barrels is paramount in controlling this yeast. Different regimes used to clean barrels include hot water, steam, $\mathrm{CO}_{2}$, and ozone. Although some of these methods are able to reduce the microbial load on the surface of the oak, they do not consistently remove tartrate build-up or penetrate and sanitize the subsurface where microbes can still survive. According to one study, culturable $D$. bruxellensis cells could be recovered from oak at a depth of up to $8 \mathrm{~mm}$ (Malfeito-Ferreira et al. 2004).

High-power ultrasonics (HPU) offers an alternative to conventional cleaning methods used in wineries. As HPU waves (20 to $100 \mathrm{kHz},>1 \mathrm{~W} / \mathrm{cm}^{2}$ ) propagate through a liquid, bubbles form and collapse, releasing their energy and creating areas of up to $5,000^{\circ} \mathrm{C}$ and $50,000 \mathrm{kPa}$ (Suslick 1989 , McClements 1995, Jayasooriya et al. 2004, Patist and Bates 2008). Application of this technology for cleaning oak barrels has shown a $>99 \%$ removal of tartrate deposits (Yap 2009). The effectiveness of this treatment in reducing the microbial load has

${ }^{1}$ School of Agriculture, Food, and Wine, The University of Adelaide, PMB 1, Glen Osmond, SA, 5064, Australia; ${ }^{2}$ Wine Innovation Cluster, Waite Campus, PMB 1, Glen Osmond, SA, 5064, Australia; and ${ }^{3}$ Cavitus Pty Ltd, P.O. Box 260, Crafers, Adelaide, SA, 5152, Australia.

*Corresponding author (e-mail: paul.grbin@adelaide.edu.au)

Acknowledgments: This research was supported under the Australian Research Council's Linkage scheme (project number LP0776588). Financial, technical, and material support was given by Cavitus Pty Ltd.

Manuscript submitted Feb 2011, revised Jun 2011, accepted Jul 2011

Copyright (C) 2011 by the American Society for Enology and Viticulture. All rights reserved.

doi: 10.5344/ajev.2011.11014 not yet been determined (Jiranek et al. 2008). Similarly, there have been no reports quantifying the ability of typical highpressure hot water (HPHW) treatments to remove microbes from oak barrels. Therefore, this study examined these two issues in parallel. The efficacy of HPU to sanitize oak barrels, at both the surface and subsurface, is also examined together with the impact of HPU treatment on the subsequent extraction of oak volatiles into the wines stored in treated barrels.

\section{Materials and Methods}

Inoculation of oak stave pieces with Dekkera bruxellensis. Stave pieces (10 cm long, $5 \mathrm{~cm}$ wide), from 1- and 3 -year-old (i.e., one or three consecutive vintages) American oak (medium toast) were floated toasted-side down in YPD broth $(300 \mathrm{~mL}, 10 \mathrm{~g} / \mathrm{L}$ yeast extract, $20 \mathrm{~g} / \mathrm{L}$ bacteriological peptone, $20 \mathrm{~g} / \mathrm{L}$ glucose) containing $0.01 \% \mathrm{w} / \mathrm{v}$ cycloheximide to suppress the growth of other yeast (Iland et al. 2007). Dekkera bruxellensis cells (AWRI 1499, 5 x $10^{7}$ cells $/ \mathrm{mL}$ ) were inoculated into this medium and incubated at $30^{\circ} \mathrm{C}$ for 5 days. The stave pieces were removed from the medium and immediately used for the respective trials. After treatment, the stave pieces were refrigerated overnight $\left(4^{\circ} \mathrm{C}\right)$ and processed the following day.

Evaluation of HPHW treatment of Dekkera-infected oak stave pieces. A head plate of a clean barrique was removed to allow attachment of the infected stave pieces onto the inside wall at the midpoint of the barrel. With the head plate replaced, the barrique was laid on its side with the bung hole facing down. A standard spray ball was inserted through the bung hole and the stave pieces washed with hot water $\left(60^{\circ} \mathrm{C}\right)$ at $1,000 \mathrm{psi}$ for 3,5 , and $8 \mathrm{~min}$, conditions typically used in industry. The control was an unwashed infected stave piece.

Evaluation of HPU treatment of Dekkera-infected oak stave pieces. A barrique standing upright, with one head plate removed, was filled with reverse osmosis water $(\sim 235 \mathrm{~L})$ at the required temperature $\left(40^{\circ}, 50^{\circ}\right.$, or $\left.60^{\circ} \mathrm{C}\right)$. To allow optimal 
transfer of energy through the liquid, the water was degassed for $10 \mathrm{~min}$ with a $4000 \mathrm{~W}$ ultrasonic unit $(20 \mathrm{kHz})$ and radial horn (Cavitus Pty Ltd., Sydney, Australia). The infected stave pieces were then attached onto the inside wall at the midpoint of the barrel farthest away from the sonitrode (Figure 1) and sonicated at maximum power $(\sim 17 \mathrm{~W} / \mathrm{L})$ for 5,8 , and $12 \mathrm{~min}$ (1-year-old oak) or 8, 12, and 15 min (3-year-old oak). Control samples were left untreated. Treatment times were based on those that were most efficient at removing tartrate deposits from oak barrels (Yap 2009).

Enumeration of Dekkera cells from oak stave cores. Triplicate core samples ( $9.5 \mathrm{~mm}$ diam, $10 \mathrm{~mm}$ thick) were removed from each stave piece (HPU treated and nontreated). To determine if HPU could affect yeast within the wood, a $2 \mathrm{~mm}$ slice was taken from the surface (representing 0 to 2 $\mathrm{mm}$ ), with a second $2 \mathrm{~mm}$ slice representing the subsurface ( 2 to $4 \mathrm{~mm}$ ). Slices were milled for $1 \mathrm{~min}$ (IKA A11 grinder/ mill; Crown Scientific, Melbourne, Australia) in $50 \mathrm{~mL}$ sterile saline $(0.9 \% \mathrm{v} / \mathrm{w})$. This method was previously validated and showed no significant loss of cell viability due to grinding (data not shown). The suspension was centrifuged at 4,500 $\mathrm{x} g$ for $5 \mathrm{~min}$, the supernatant discarded and the pellet resuspended in $1 \mathrm{~mL}$ sterile saline $(0.9 \% \mathrm{v} / \mathrm{w})$. Serial dilution aliquots $(10 \mu \mathrm{L})$ of the milled samples and the controls were spot-plated in triplicate onto YPD agar plates containing $0.01 \%(\mathrm{w} / \mathrm{v})$ cycloheximide, incubated for 3 to 5 days $\left(30^{\circ} \mathrm{C}\right)$ and colonies were counted (method modified from Iland et al. 2007). Colony forming units (cfu) were calculated per unit volume of the core slice $\left(\sim 143 \mathrm{~mm}^{3}\right)$ and expressed as culturable cells per $\mathrm{mm}^{3}$ of wood.

Oak volatile extraction from oak barrels into wine over 12 months. All barrels (1- and 3-year-old red wine barriques) used in this trial were of American oak, $\mathrm{M}+$ toast (World Cooperage, Tanunda, Australia) and were filled with a 2008 vintage Barossa Shiraz wine after treatment. Three barrel wash treatments were compared: high-pressure hot water (HPHW) at $1,000 \mathrm{psi}$ and $60^{\circ} \mathrm{C}$, mains pressure cold water $(\mathrm{MPCW})$ at $13^{\circ} \mathrm{C}$, and high-power ultrasonics (HPU)

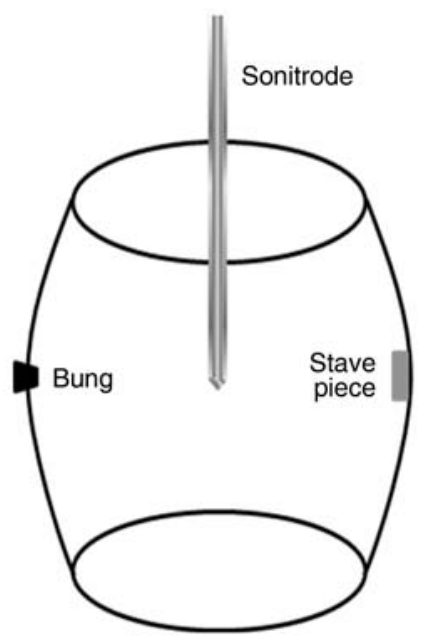

Figure 1 Experimental setup with the position of Dekkera bruxellensis AWRI 1499-infected stave pieces within a water-filled barrel for HPU treatment. at $60^{\circ} \mathrm{C}$. One-year-old barrels were washed for $5 \mathrm{~min}$ and 3 -year-old barrels for $8 \mathrm{~min}$. Following cleaning, all barrels were filled with the 2008 Shiraz. Wine compositional analyses were performed (in duplicate) using standard methods and included $\mathrm{pH}$, titratable acidity (TA), free and total sulfur, acetic acid, and ethanol. Oak flavor analysis (Table 1) was performed by Commercial Services (Australian Wine Research Institute).

Sensory analysis. Duo trio analysis of wines was performed in a purpose-built sensory laboratory at the Waite Campus of the University of Adelaide. From the oak volatile and chemical analyses it was deemed that replicates within treatments were not significantly different in their compositional profiles, therefore replicate wines were blended immediately before sensory evaluation. Panelists (32, approximately 50/50 male/female and aged between 23 and 70) were regular consumers of red wine and $\sim 90 \%$ had formal sensory (difference) testing experience. Each panelist was seated in an individual booth separated from their neighbor by a partition and did not communicate with other panelists during the testing. Water was provided to cleanse their palates between wines. Wines $(30 \mathrm{~mL})$ were presented in random order against the reference in randomly coded ISO standard tasting glasses and assessed at room temperature $\left(25^{\circ} \mathrm{C}\right)$ by taste and smell. Each panelist was asked to pick the wine that she or he perceived to be the same as the reference. Significant differences were calculated at $\alpha=0.05$ using the critical number of correct responses for a duo trio test (Modified Roessler Table; Lawless and Heymann 1999).

Statistical analysis. One-way ANOVA $(p=0.05)$ with Tukey's multiple comparison post-test was performed using GraphPad Prism version 5.00 for Windows (GraphPad Software, San Diego, CA).

\section{Results}

Effect of HPHW on D. bruxellensis culturability, 1-year oak. Infected stave pieces were mounted onto the inside wall of an oak barrel. A spray ball was inserted through the bung hole and the barrel washed with hot water $\left(60^{\circ} \mathrm{C}\right)$ for 3,5 , and $8 \mathrm{~min}$. These times were chosen to reflect wash times

\begin{tabular}{lc}
\hline \multicolumn{2}{c}{ Table 1 Oak-derived flavor compounds quantifiable } \\
by the AWRI method.
\end{tabular}

aThese compounds are not oak flavor compounds but are indicative of metabolite products of Brettanomyces/Dekkera yeast.

${ }^{\mathrm{b}}$ Represent the limits of analytical detection. 
commonly used in the wine industry. Surface and subsurface cores were taken from the stave pieces for each treatment time and recoverable $D$. bruxellensis cells determined. After 3 min of washing, the number of culturable cells recovered from the surface was approximately $2 \%$ of the $\sim 8,000$ cells recovered from the untreated stave (Figure 2A). Longer wash times (5 and $8 \mathrm{~min}$ ) did not significantly reduce the culturable cell count any further. In the subsurface, culturable cells were reduced by $\sim 50 \%$ after 3 min (Figure $2 \mathrm{~B}$ ) and similar to the surface, no significant reduction with longer wash times was observed.

Effect of HPU on D. bruxellensis culturability, 1-year oak. Culturability of D. bruxellensis associated with surface and subsurface slices of 1-year-old stave pieces was determined after 5,8 , and $12 \mathrm{~min}$ of exposure to $\mathrm{HPU}$, each at water temperatures of $40^{\circ} \mathrm{C}, 50^{\circ} \mathrm{C}$, and $60^{\circ} \mathrm{C}$. The surface slice of the control (untreated) stave showed a high cell population $\left(\sim 6,000 \mathrm{cfu} / \mathrm{mm}^{3}\right.$; Figure $\left.3 \mathrm{~A}\right)$. When comparing the control to HPU-treated samples, there was a reduction of up to several orders of magnitude in culturable cell numbers (i.e., to $\sim 50-200 \mathrm{cfu} / \mathrm{mm}^{3}$ ). Culturable cells were evident for all time points at $40^{\circ} \mathrm{C}$, and for 5 and $8 \mathrm{~min}$ exposure at $50^{\circ} \mathrm{C}$. No culturable cells were detected after 12 min exposure at $50^{\circ} \mathrm{C}$, or for any treatment time examined at $60^{\circ} \mathrm{C}$.

As expected, the number of culturable cells in the underlying $2 \mathrm{~mm}$ below the surface of the control stave was considerably lower compared to the surface (i.e., $\sim 20$ versus
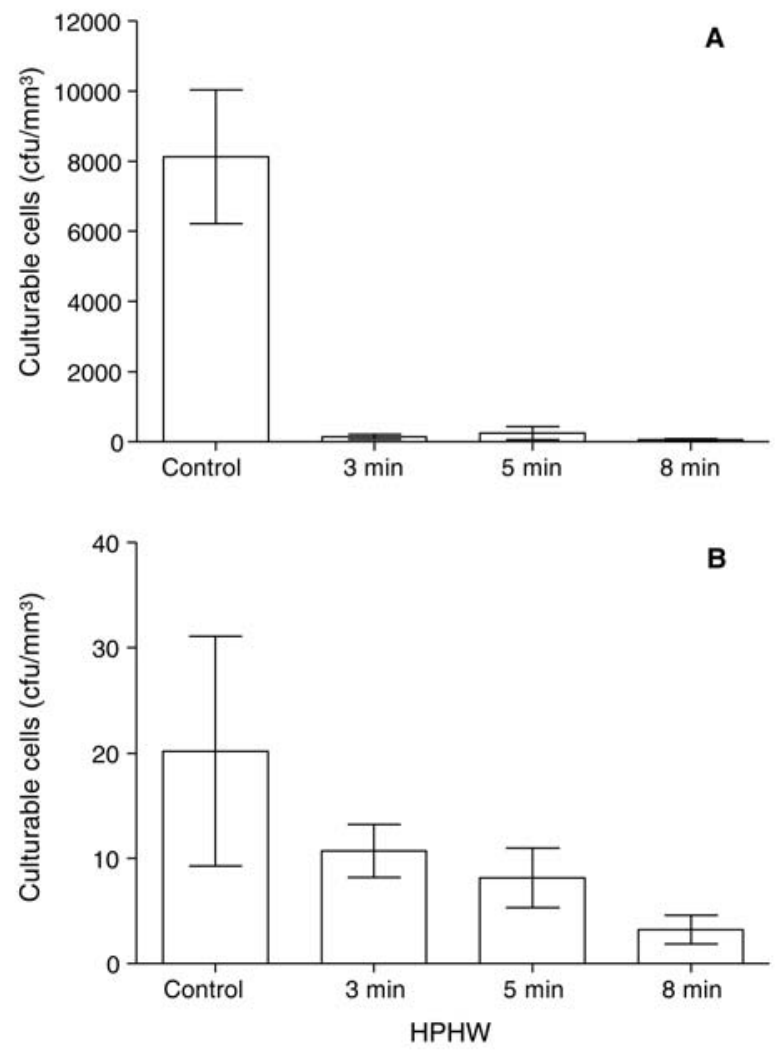

Figure 2 Dekkera bruxellensis culturability at the surface $(0$ to $2 \mathrm{~mm}$, A) and subsurface (2 to $4 \mathrm{~mm}$, B) of 1-year-old oak after HPHW $\left(60^{\circ} \mathrm{C}\right)$ at various treatment times. Error bars represent standard deviation of triplicate core samples analyzed in duplicate.
$6,000 \mathrm{cfu} / \mathrm{mm}^{3}$; Figure 3B). However, significant decreases in culturable cells occurred at this depth for all temperatures after HPU treatment, with no culturable cells detected after 12 min exposure at $50^{\circ} \mathrm{C}$, or at any time at $60^{\circ} \mathrm{C}$.

Effect of HPU on D. bruxellensis culturability, 3-year oak. The wood of 3-year-old stave pieces showed greater deterioration compared to the surface of the 1-year-old staves (data not shown). Both surface and subsurface samples of control staves were highly contaminated with $D$. bruxellensis cells, with the subsurface of the control showing a higher level of infection $\left(\sim 80 \mathrm{cfu} / \mathrm{mm}^{3}\right)$ compared to the 1-year-old subsurface $\left(\sim 20 \mathrm{cfu} / \mathrm{mm}^{3}\right)$. Similar to the 1-year-old wood, sonication of the 3-year-old wood reduced the surface culturable cell count by several orders of magnitude after $8 \mathrm{~min}$ of treatment at $40^{\circ} \mathrm{C}$ (Figure 4A), and no culturable cells were detected on the surface slice after $8 \mathrm{~min}$ at $50^{\circ} \mathrm{C}$ or at exposures of $60^{\circ} \mathrm{C}$ (Figure 4A). The culturable cells from the subsurface slice also decreased significantly after even the least severe treatment $\left(40^{\circ} \mathrm{C}, 8 \mathrm{~min}\right)$ with no culturable cells detected after $15 \mathrm{~min}$ at $50^{\circ} \mathrm{C}$, or after any treatment duration at $60^{\circ} \mathrm{C}$ (Figure 4B).

Effect on oak volatile extraction into wine stored in HPU-treated oak barrels. None of the 12-month-old wines aged in 1- or 3-year-old barrels contained any detectable
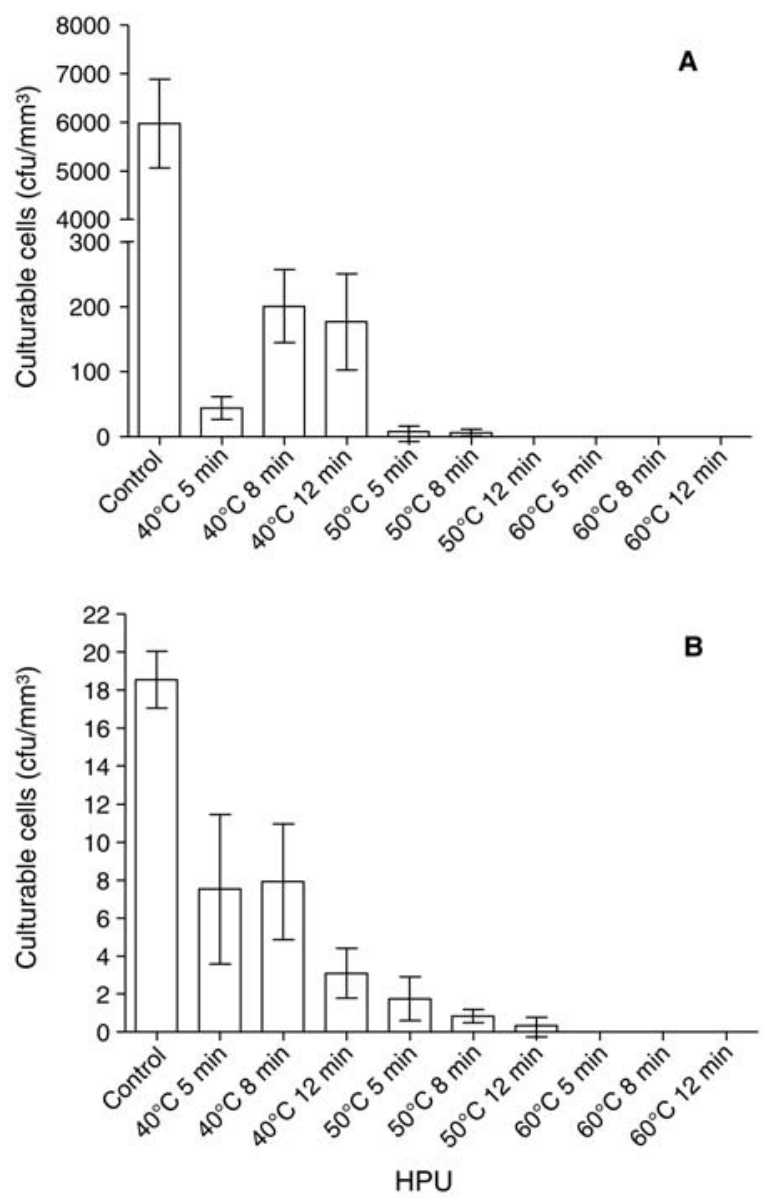

Figure 3 Dekkera Bruxellensis culturability at the surface (0 to $2 \mathrm{~mm}, \mathbf{A})$ and subsurface (2 to $4 \mathrm{~mm}$, B) of 1-year-old oak after HPU exposure at various temperatures and treatment times. Error bars represent standard deviation of triplicate core samples analyzed in duplicate. 
concentrations of 4-ethylphenol or 4-ethylguaiacol (data not shown), which are compounds indicative of possible $D$. bruxellensis spoilage (Harris et al. 2009). Changes in wine composition that occurred over 12 months storage in 1-year- old barrels followed the same trends regardless of the wash treatment used for the barrels, with no significant differences apparent in final $\mathrm{pH}, \mathrm{TA}$, acetic acid, ethanol, and free and total $\mathrm{SO}_{2}$ levels (Figure 5). Prior to bottling (day 361), $\mathrm{pH}$
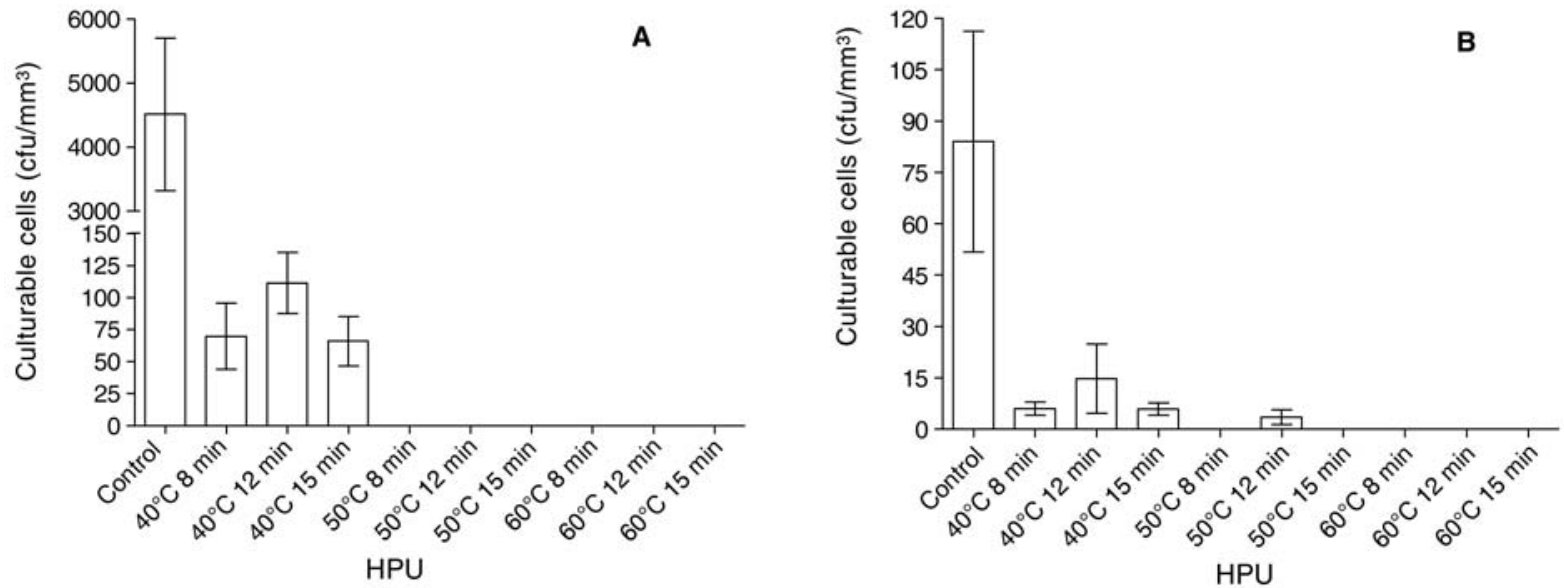

Figure 4 Dekkera bruxellensis culturability at the surface (0 to $2 \mathrm{~mm}, \mathbf{A}$ ) and subsurface (2 to $4 \mathrm{~mm}$, B) of 3-year-old oak after HPU exposure at various temperatures and treatment times. Error bars represent standard deviation of triplicate core samples analyzed in duplicate.
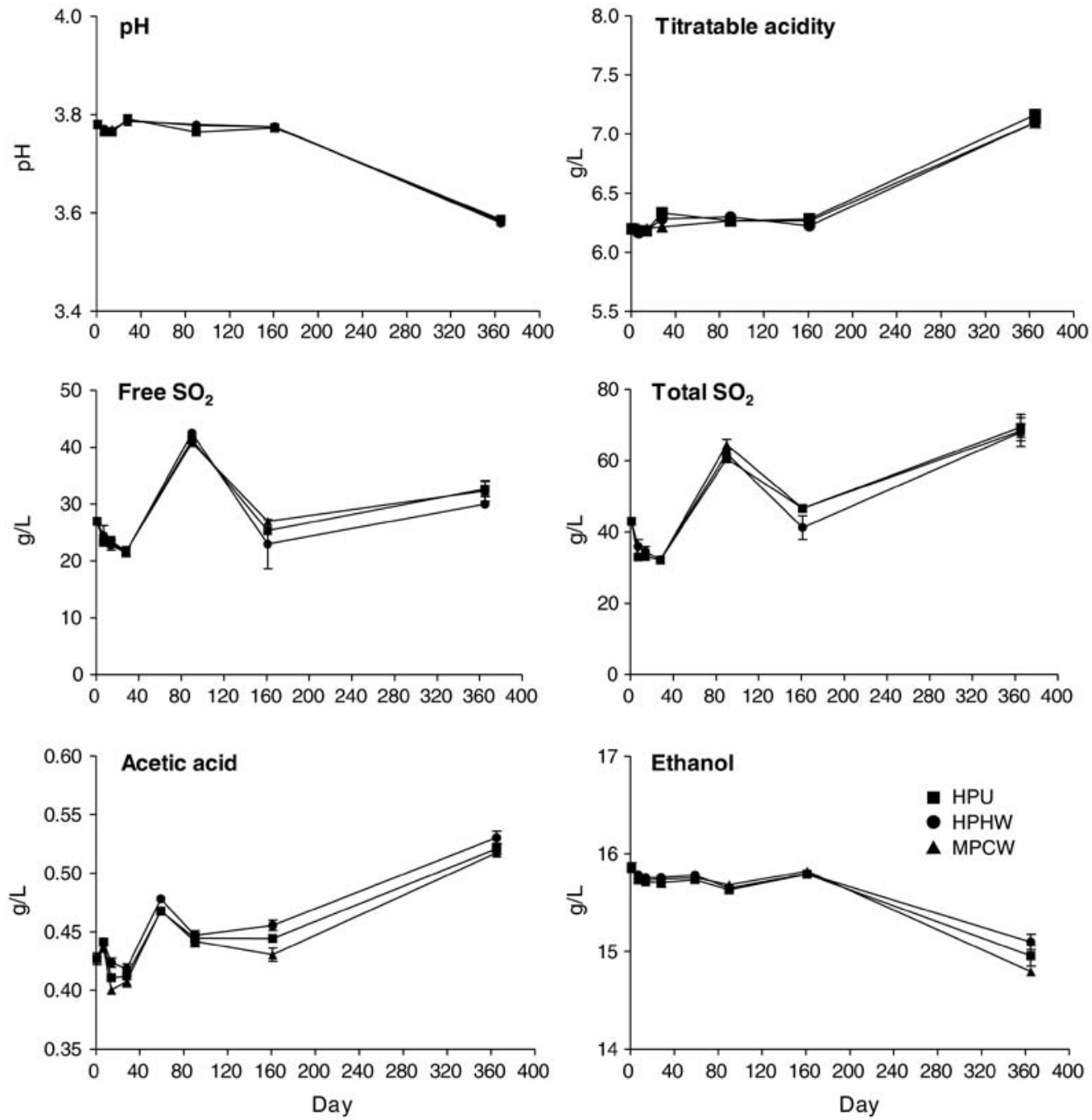

Figure 5 Chemical profiles of wines aged for 12 months in 1-year-old barrels initially washed with HPU, HPHW, and MPCW. Mean values are from triplicate barrels analyzed in duplicate with error bars representing standard deviation. 
was adjusted to 3.6 by addition of $1 \mathrm{~g} / \mathrm{L}$ tartaric acid, which explains the decrease in $\mathrm{pH}$ and the increase in tartaric acid. At this time free $\mathrm{SO}_{2}$ was adjusted to $\sim 30-5 \mathrm{ppm}$, which is reflected in the increase in total $\mathrm{SO}_{2}$.

After 12 months of storage, oak volatile analysis clearly showed that volatile compounds were still being extracted into the wine (Figure 6). However, any significant differences between barrel washing treatments, evident only at days 90 and 161 for cis-oak lactone, were not significant at day 361. There were no significant differences between barrel treatments for the other oak volatile compounds at any given time point. Furfural and 5-methylfurfural extraction into wines from all treated barrels appeared to plateau; however, no firm conclusion is possible since the variation between replicates was quite large (Figure 6). This variation was most likely due to differences between individual barrels within this set of replicates: furfural and 5-methylfurfural are formed due to the degradation of cellulose and hemicellulose during the toasting process, and slight variations in toasting levels can affect the relative amount of these compounds (Towey and Waterhouse 1996a).

The chemical profiles of the wines aged for 12 months in 3 -year-old barrels (Figure 7) showed no significant differences in $\mathrm{pH}$, TA, or ethanol concentrations. The apparent
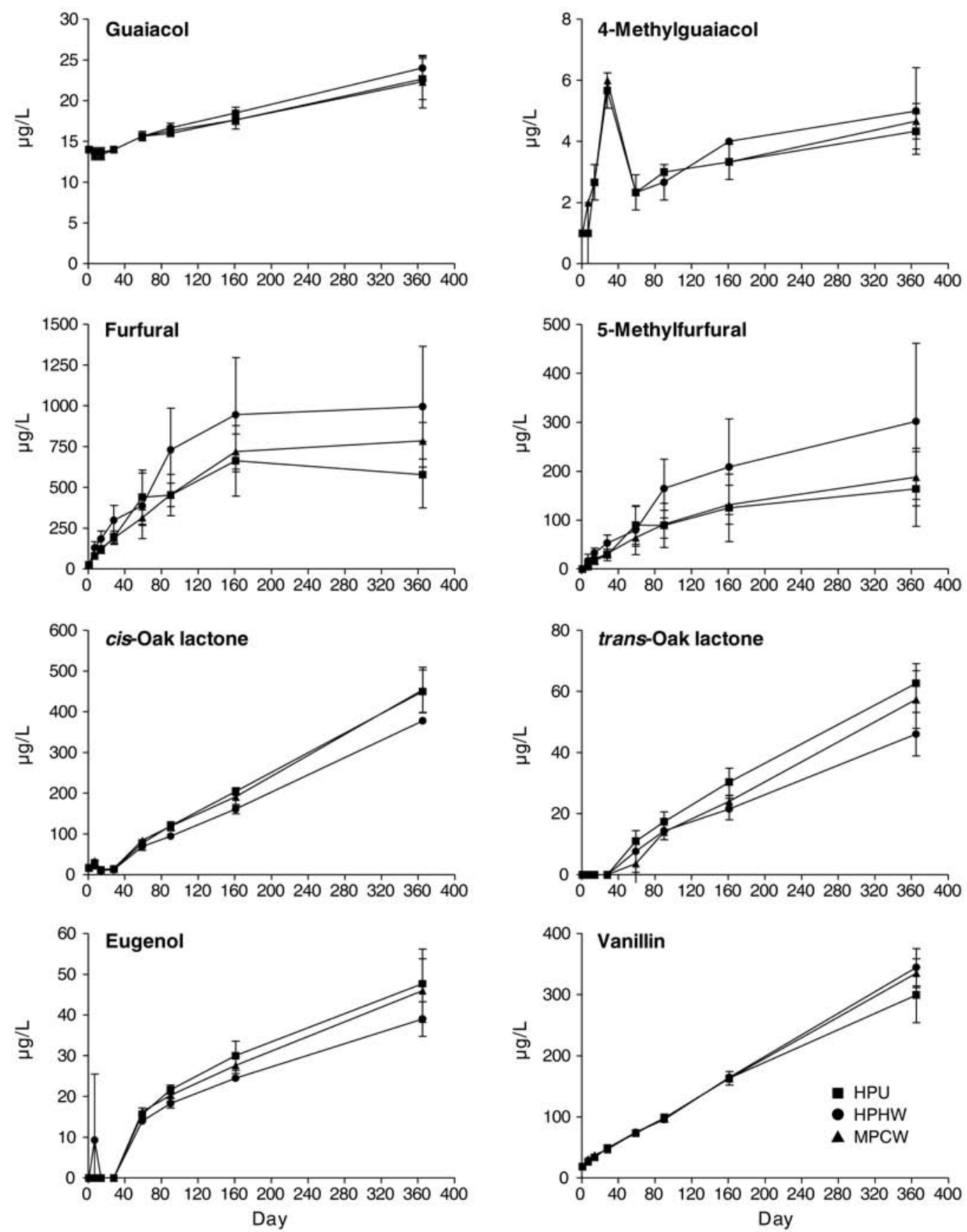

Figure 6 Volatile oak flavor extraction profiles of wines aged for 12 months in 1-year-old barrels initially washed with HPU, HPHW, and MPCW. Mean values are from triplicate barrels with error bars representing standard deviation. 
significant differences in free $\mathrm{SO}_{2}$ and total $\mathrm{SO}_{2}$ were not attributed to barrel wash treatment but rather to slight variations in $\mathrm{SO}_{2}$ addition before bottling. Wines from the MPCWwashed barrel contained significantly less acetic acid $(\sim 0.07$ $\mathrm{g} / \mathrm{L}$ less) than wines from barrels washed by either HPU or HPHW. Although this difference was statistically significant, it is unlikely to be of sensory importance since all totals were about half the sensory threshold of acetic acid in wine (Corison et al. 1979, Amerine and Roessler 1983).

A comparison of trends for the extraction of oak volatiles into the wine stored in 1-year-old (Figure 6) compared to 3 -year-old barrels (Figure 8) revealed similar trends. Key differences were related to the absolute amount of the given volatile extracted into the wine, with these amounts typically lower for the wine from 3-year-old barrels, as could be expected.

For a duo trio test with 32 panelists (1-year-old oak), the critical value at $5 \%$ probability was 22 and with 31 panelists (3-year-old), the critical value at $5 \%$ probability was 21 (Lawless and Heymann 1999). In all six tests, less than the critical number of panelists correctly matched the sample to
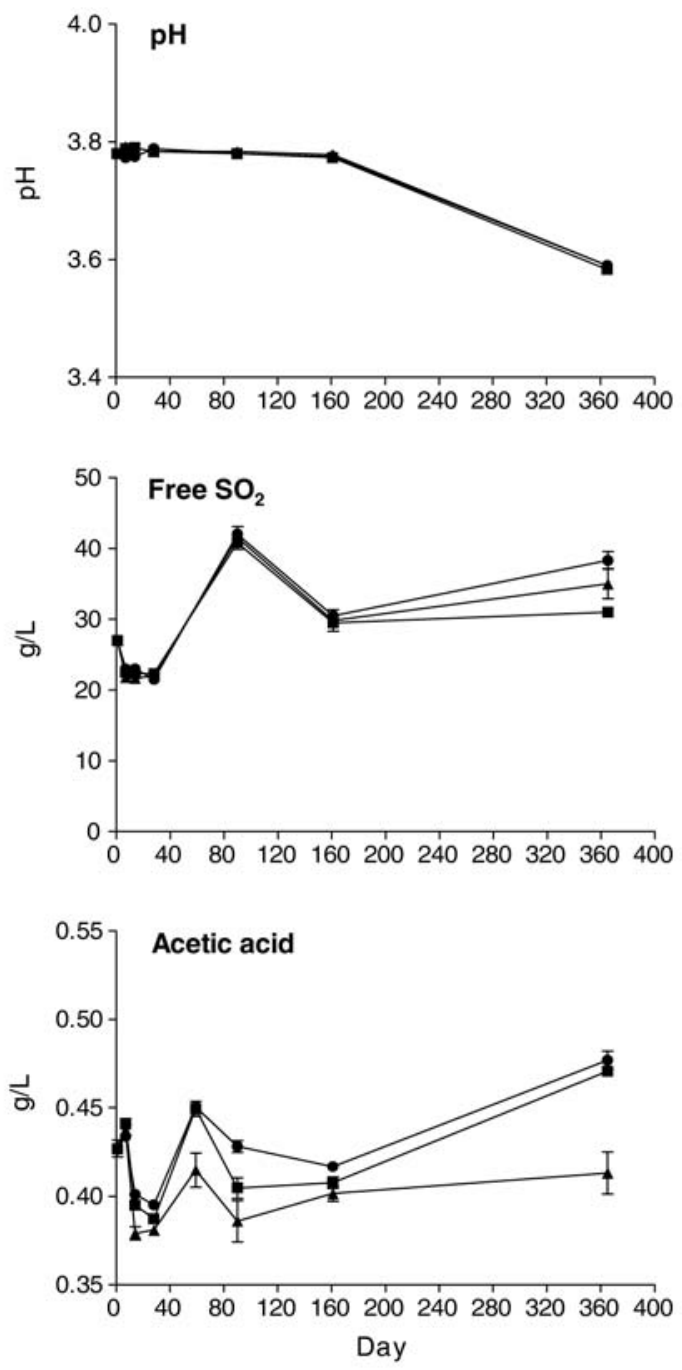

the reference (Table 2), indicating the wines could not be distinguished based on the barrel, and therefore wash treatment, in which the wine had been aged.

\section{Discussion}

Results demonstrate that hot water washing of barrels reduces the microbiological load, but does not satisfactorily sanitize the surface of wine barrels (Figure 2). Of even more concern to winemakers, culturable microorganisms, in this case D. bruxellensis, may persist below the surface of the oak. Other studies have shown that this organism can been found at a depth of up to $8 \mathrm{~mm}$, which is well within the region that wine soaks into the wood (Malfeito-Ferreira et al. 2004). Thus, remaining viable cells would have the potential to infect new wine aged in these barrels. Although HPHW might be able to completely eliminate contaminating yeast with an extension of the typical treatment duration, confirmation of this possibility was beyond the scope of this study and was not pursued, partly because such treatments will result in greater water usage where no recycling process is in place.
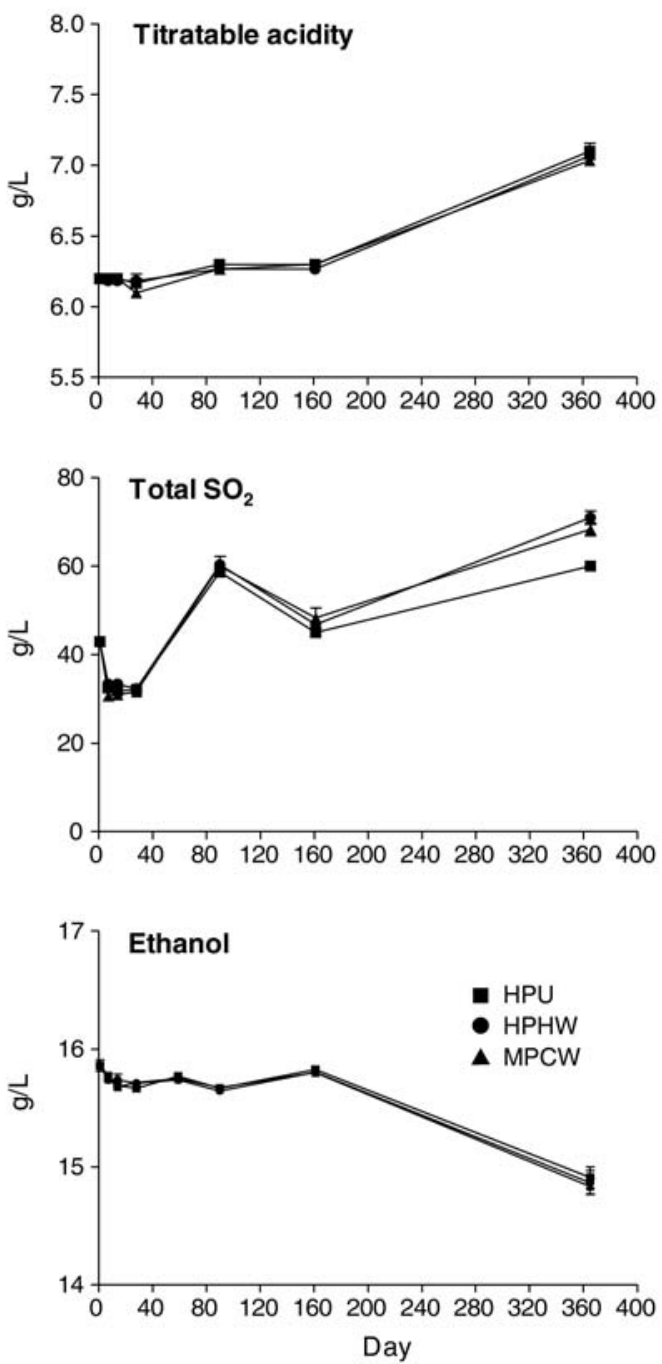

Figure 7 Chemical profiles of wines aged for 12 months in 3-year-old barrels initially washed with HPU, HPHW, and MPCW. Mean values are from triplicate barrels with error bars representing standard deviation. 
As an alternative, HPU in conjunction with hot water at $40^{\circ} \mathrm{C}$ produced comparable reductions in microbial load compared to standard hot water washing alone $\left(60^{\circ} \mathrm{C}\right)$. Where HPU was used in combination with the same water temperature as used for $\mathrm{HPHW}$ (i.e., $60^{\circ} \mathrm{C}$ ) all culturable cells could be eliminated on the surface and subsurface of 1-year-old and 3 -year-old infected oak. The synergy between the effects of hot water and HPU is well known for inactivation of microbes in aqueous solution (Ciccolini et al. 1997, Villamiel and de Jong 2000, Piyasena et al. 2003); however, subsurface sanitization of porous substrates, like oak, has not been demonstrated previously. The HPU procedure used for clearing barrels of tartrates therefore is additionally capable of elimination
Table 2 Duo trio analysis of 12-month-old wines from barrel replicates treated with HPHW, MPCW, and HPU.

\begin{tabular}{lcccc}
\hline Wine $^{\text {a }}$ & Correct & Incorrect & $\begin{array}{c}\text { Critical value } \\
(\boldsymbol{\alpha}<\mathbf{0 . 0 5})\end{array}$ & Signf $^{b}$ \\
\hline HPHW1 vs MPCW1 & 19 & 13 & 22 & $\mathrm{~ns}$ \\
HPHW1 vs HPU1 & 15 & 17 & 22 & $\mathrm{~ns}$ \\
MPCW1 vs HPU1 & 11 & 21 & 22 & $\mathrm{~ns}$ \\
HPHW3 vs MPCW3 & 15 & 16 & 21 & $\mathrm{~ns}$ \\
HPHW3 vs HPU3 & 12 & 19 & 21 & $\mathrm{~ns}$ \\
MPCW3 vs HPU3 & 11 & 20 & 21 & $\mathrm{~ns}$ \\
\hline
\end{tabular}

aHPHW: high-pressure hot water; MPCW: mains pressure cold water; HPU: high-power ultrasonic. 1 (1 year) and 3 (3 years) indicate the age of the barrels.

${ }^{b}$ ns indicates not significant.
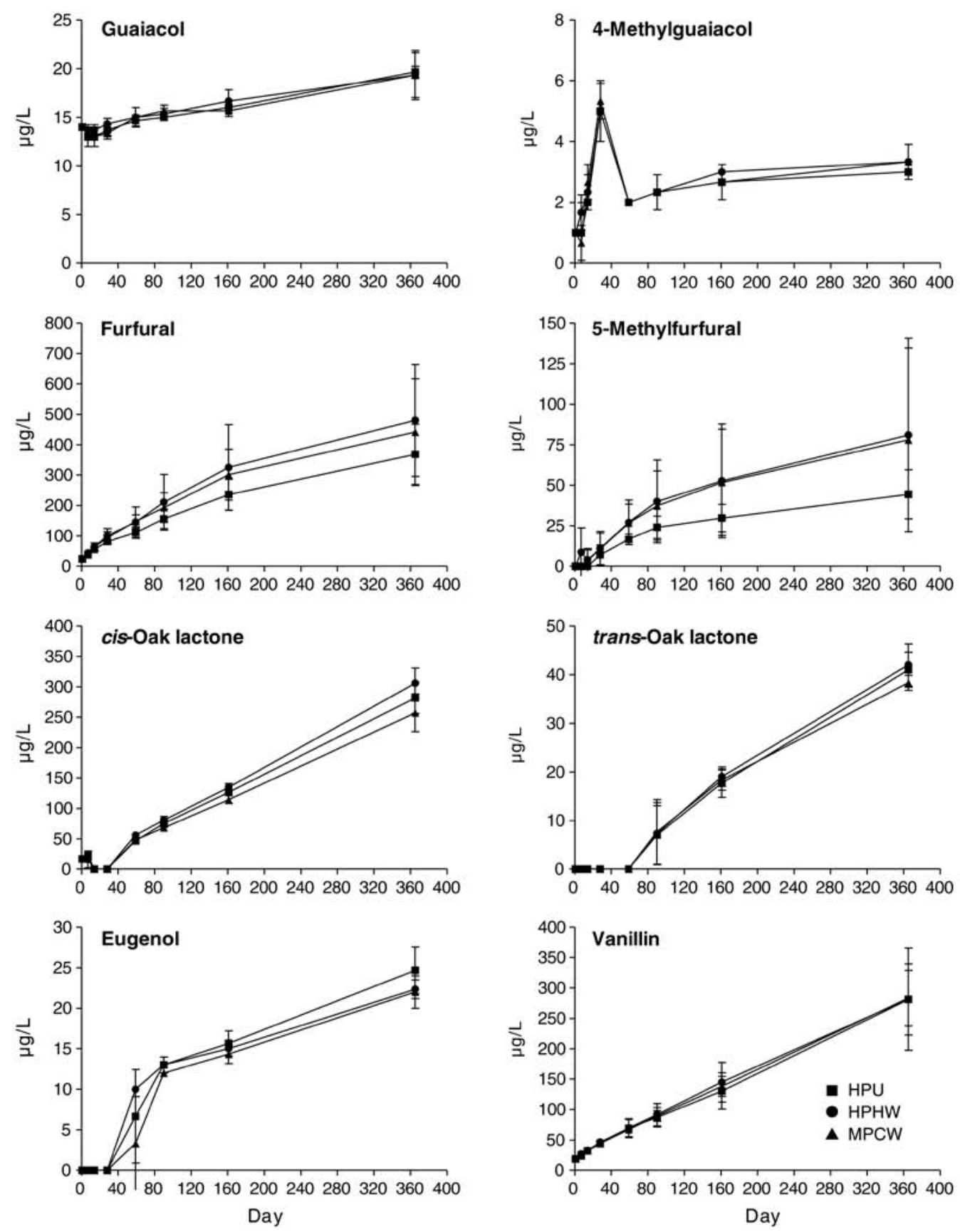

Figure 8 Oak flavor extraction profiles of wines aged for 12 months in 3-year-old barrels initially washed with HPU, HPHW, and MPCW. Mean values are from triplicate barrels with error bars representing standard deviation. 
of deliberately introduced D. bruxellensis yeast, at least as detected by plating.

The function of aging wine (predominantly red) in oak barrels is to stabilize wine color and add to sensory properties (Ribéreau-Gayon et al. 2006). Barrel-cleaning methods must not compromise these desirable properties. Barrels (1- and 3-year-old) washed with cold and hot water (as commonly used in most wineries) and a combination of hot water and HPU were compared for to determine the effect of wash treatment on oak volatile release into red wine over a 12-month period. All the wines from both 1- and 3-year-old barrels, irrespective of treatment, displayed similar chemical parameters $\left(\mathrm{pH}, \mathrm{TA}\right.$, free $\mathrm{SO}_{2}$, total $\mathrm{SO}_{2}$, acetic acid, and ethanol), indicating that the age of the barrel had little, if any, influence on these measured parameters. As expected and previously shown (Towey and Waterhouse 1996b), oak volatiles measured in wines from 3-year-old barrels were at lower concentrations compared to wines from 1-year-old barrels. This is mainly attributable to the degradation and extraction of oak volatiles from the toasted layer over subsequent vintages (Towey and Waterhouse 1996b, RibéreauGayon et al. 2006).

The cleaning methods used in this study led to no significant differences in the oak volatiles extracted into the wines when comparing within the 1- and 3-year-old oak groups, suggesting that the wash treatments compared had no impact on the overall extraction of oak volatiles into the wine. This finding was further confirmed with differential sensory analyses in which panel members found no differences in the wines from the three wash treatments of either oak age.

\section{Conclusions}

In winemaking, oak barrels are prone to tartrate build-up and, if not cleaned properly, microbial spoilage. Traditional hot water washing is widely recognized as incomplete in its effectiveness in removing tartrate deposits and cannot sanitize the underlying porous surface of oak. Application of HPU in conjunction with hot water of at least $60^{\circ} \mathrm{C}$, a regime promoted for complete removal of tartrate deposits, was also able to remove culturable $D$. bruxellensis inoculated on the surface and up to $4 \mathrm{~mm}$ into the oak itself. No adverse effects on oak volatile extraction into wine stored in HPU-treated barrels were observed.

\section{Literature Cited}

Amerine, M.A., and E.B. Roessler. 1983. Wines: Their Sensory Evaluation. W.H. Freeman, New York.

Ciccolini, L., P. Taillandier, A.M. Wilhem, H. Delmas, and P. Strehaiano. 1997. Low frequency thermo-ultrasonication of Saccharomyces cerevisiae suspensions: Effect of temperature and of ultrasonic power. Chem. Eng. J. 65:145-149.
Corison, C.A., C.S. Ough, H.W. Berg, and K.E. Nelson. 1979. Must acetic acid and ethyl acetate as mold and rot indicators in grapes. Am. J. Enol. Vitic. 30:130-134.

Harris, V., C. Ford, V. Jiranek, and P. Grbin. 2009. Survey of enzyme activity responsible for phenolic off-flavour production by Dekkera and Brettanomyces yeast. Appl. Microbiol. Biotechnol. 81:1117-1127.

Iland, P., P. Grbin, M. Grinbergs, L. Schmidtke, and A. Soden. 2007. Microbiological Analysis of Grapes and Wine: Techniques and Concepts. Patrick Iland Wine Promotions, Campbelltown, Australia.

Jayasooriya, S.D., B.R. Bhandari, P. Torley, and B.R. D'Arcy. 2004. Effect of high power ultrasound waves on properties of meat: A review. Int. J. Food Prop. 7:301-319.

Jiranek, V., P. Grbin, A. Yap, M. Barnes, and D. Bates. 2008. High power ultrasonics as a novel tool offering new opportunities for managing wine microbiology. Biotechnol. Lett. 30:1-6.

Lawless, H.T., and H. Heymann. 1999. Sensory Evaluation of Food: Principles and Practices. Kluwer Academic/Plenum Publishers, New York.

Loureiro, V., and M. Malfeito-Ferreira. 2003. Spoilage yeasts in the wine industry. Int. J. Food Microbiol. 86:23-50.

Malfeito-Ferreira, M., P. Laureano, A. Barata, I. D’Antuono, H. Slender, and V. Loureiro. 2004. Effect of different barrique sanitation procedures on yeasts isolated from the inner layers of wood. Abstr. Am. J. Enol. Vitic. 55:304A.

McClements, D.J. 1995. Advances in the application of ultrasound in food analysis and processing. Trends Food Sci. Technol. 6:293-299.

Oelofse, A., I.S. Pretorius, and M. du Toit. 2008. Significance of Brettanomyces and Dekkera during winemaking: A synoptic review. S. Afr. J. Enol. Vitic. 29:128-144.

Patist, A., and D. Bates. 2008. Ultrasonic innovations in the food industry: From the laboratory to commercial production. Innov. Food Sci. Emerg. Technol. 9:147-154.

Piyasena, P., E. Mohareb, and R.C. McKellar. 2003. Inactivation of microbes using ultrasound: A review. Int. J. Food Microbiol. 87:207-216.

Ribéreau-Gayon, P., Y. Glories, A. Maujean, and D. Dubourdieu. 2006. Handbook of Enology. Vol. 2. The Chemistry of Wine and Stabilization and Treatments. Wiley \& Sons, Chichester, UK.

Suslick, K.S. 1989. The chemical effects of ultrasound. Sci. Am. 260:80-86.

Towey, J.P., and A.L. Waterhouse. 1996a. Barrel-to-barrel variation of volatile oak extractives in barrel-fermented Chardonnay. Am. J. Enol. Vitic. 47:17-20

Towey, J.P., and A.L. Waterhouse. 1996b. The extraction of volatile compounds from French and American oak barrels in Chardonnay during three successive vintages. Am. J. Enol. Vitic. 47:163-172.

Villamiel, M., and P. de Jong. 2000. Inactivation of Pseudomonas fluorescens and Streptococcus thermophilus in Trypticase (R) soy broth and total bacteria in milk by continuous-flow ultrasonic treatment and conventional heating. J. Food Eng. 45:171-179.

Yap, A. 2009. Cleaning and disinfecting barrels with high power ultrasonics: A new industry benchmark. Aust. N.Z. Grapegr. Winemaker 551:89-93. 